\title{
Evaluation of antifungal activity of three essential oils against selected isolates of Penicillium, Purpureocillium and Acremonium
}

\author{
Lukasz Kręcidło*, Teresa Krzyśko-Łupicka
}

Independent Department of Biotechnology and Molecular Biology, Faculty of Natural Sciences and Technology, University of Opole, Oleska 48 St, 45-052 Opole, Poland,

*e-mail:1.krecidlo@gmail.com

Received: 06 October 2017 /Accepted: 19 November 2017

\begin{abstract}
Storage is a critical process of food production because incorrect conditions during this process lead to the growth of economic costs caused by material loss. It is important to maintain adequate microbiological purity of storage areas. The development of microbes present in warehouses may lead to secondary contamination of stored materials and reduce their quality. The aim of the study was to evaluate the effect of essential oils on the growth of Acremonium strictum, Penicillium citrinum, Penicillium expansum and Purpureocillium lilacinum. Fungal strains were isolated from the food warehouse. Studies on the influence of selected mix of phenolic substances were performed using three commercially available essential oils, namely rosewood, rosemary and thyme. Evaluation of antifungal activity of these essential oils was done by plate dilution method and expressed as inhibition rate of mycelial growth and index of mycelial growth, and by minimal inhibitory concentration (MIC) and minimal fungicidal concentration (MFC) assays. Thyme oil showed the highest antifungal activity and inhibited growth of all fungal strains at the lowest tested concentration $\left(1 \mu \mathrm{L} \mathrm{mL} \mathrm{L}^{-1}\right)$. Penicillium expansum strain was found to be the most resistant to the tested essential oils.
\end{abstract}

Key words: essential, oils, moulds, storage, food industry.

\section{Introduction}

Storage of raw materials and products is a critical step in food production. Inappropriate conditions during the storage process may promote the development of microorganisms present in warehouse environment. One of the most important issue is the presence and development of moulds, which may affect the quality of raw materials. These microorganisms may decrease the nutrient value of stored food products and/or cause their contamination with mycotoxins. Consequently, such raw vegetables, cereals and fruits can compromise a consumer health and generate economic losses (Kedia et al., 2015). It is claimed that 25 to $40 \%$ of world cereal production is contaminated with fungal secondary metabolites (Pereira et al., 2014). To counteract the fungal contamination, especially in the agri-food industry, the chemical disinfectants are used (Ajayi \& Fuchs, 2015). However, moulds has increasingly become resistant to fungicides (Lima et al., 2015). Alternatively, plant-derived compounds such as essential oils exhibit antimicrobial properties (Raut \& Karuppayil, 2014). Essential oils are natural volatile aromatic compounds characterized by strong odour (Burt, 2004). They may inhibit mycelial growth and thereby prevent secretion of fun- 
gal toxins (Gemeda et al., 2014a; Kohiyama et al., 2015). The Food and Drug Administration (FDA) in 21st Federal Code 182.20 recognized essential oils as safe (U.S. CFR, 2015). Moreover, their proved antimicrobial properties make essential oils an alternative to chemical fungicides.

The aim of the study was to evaluate the effect of essential oils on the growth of Acremonium strictum (W. Gams), Penicillium citrinum (Thom), Penicillium expansum (Thom) and Purpureocillium lilacinum (Thom), which were, isolated from the warehouse environment.

\section{Material and methods}

Fungal strains were isolated from air of food warehouses in the Opole Voivodship (Poland) by volumetric method using MAS-100 air sampler (Millipore) on the Perti plates with CYA medium. Thyme essential oil from Thymus vulgaris herb, rosewood essential oil from Aniba rosaeodora and rosemary essential oil from rosemary herb (Rosmarinus officinalis), available in the Polish market, were analysed. According to the manufacturer's declaration tested essential oils contained no additional synthetic chemicals or unnatural ingredients and were stored in dark glass bottles at $4^{\circ} \mathrm{C}$.

The composition of essential oils was determined by gas chromatography coupled with mass spectrometry (GC/MS). The analysis was performed using gas chromatograph (HP 6890, Hewlett-Packard) coupled with Mass Spectrometer (HP 5973A, Hewlett-Packard). The non-polar capillary column HP-5MS (5\% - diphenyl, 95\% dimethylpolysiloxane) was used, with a length of $30 \mathrm{~m}$, an internal diameter of $0.25 \mathrm{~mm}$, and film thickness of $0.25 \mu \mathrm{m}$. Helium was used as carrier gas. The analysis was performed at a temperature range of $60-280^{\circ} \mathrm{C}$ and the heating rate was $10^{\circ} \mathrm{C} \mathrm{min}^{-1}$. The volume of the oil solution in dichloromethane sample was $1 \mu \mathrm{l}(1: 50, v / v)$.

The fungicidal and fungistatic activity of essential oils was determined for the filamentous fungi, viz. Acremonium strictum, Penicillium citrinum, Penicillium expansum and Purpureocillium lilacinum.

Fungistatic activity of essential oils was assessed using the agar dilution method described by Soliman and Badeaa (2002) and Feng et al. (2011). Czapek Dox Agar (CYA) was combined with proper essential oil at their final concentrations of $1,5,10,15$ and $20 \mu \mathrm{L} \mathrm{mL}^{-1}$. A positive control was the CYA medium containing a peracetic acid based disinfectant at a final concentration of $3 \mu \mathrm{L} \mathrm{mL}{ }^{-1}$. Negative control was an unmodified CYA medium. The assay was performed in 4 replications, plates were incubated at $25^{\circ} \mathrm{C}$ for 10 days. The diameter of fungal growth was measured once a day. Briefly, molted CYA medium was combined with essential oil to obtain its required final concentration. Agar medium was allowed to solidify. The discs $(10 \mathrm{~mm})$ of fungal growth were then placed on the surface of agar medium. Discs with fungal growth were cut with sterile cork borer from plated with fungal growth on Czapek Dox Agar (CYA) after incubation at at $25^{\circ} \mathrm{C}$ for 10 days Fungistatic activity of tested oils was determined by calculation of percent of fungal growth inhibition using Abbott's formula (Borecki, 1984):

$$
\mathrm{I}=(\mathrm{C}-\mathrm{M}) / \mathrm{C} \times 100
$$

I - fungus linear growth inhibition index [\%], $\mathrm{C}$ - fungal colony diameter on the control plate [mm], $\mathrm{M}$ - fungal colony diameter on plate containing a tested substance $[\mathrm{mm}]$.

Index of linear growth (T) was determined by measures of growth of fungal mycelium and is described by following formula: (Gleń \& Boligłowa, 2012):

$$
\mathrm{T}=\mathrm{A} / \mathrm{D}+\mathrm{b} 1 / \mathrm{d} 1+\mathrm{bx} / \mathrm{dx}
$$

$\mathrm{T} \quad-$ index of linear growth,

A - average measurement value of diameter colonies [mm],

D - duration of the experiment,

b1...bx - increase in colonies diameter [mm],

$\mathrm{d} 1 \ldots \mathrm{dx}$ - number of days since last measurement.

Minimal inhibitory concentration were carried in triplicate and minimum fungicidal concentration of essential oils against moulds were also determined but in one repeat. MIC is defined as the lowest concentration of essential oil, which causes visual inhibition of mycelium growth when compared to negative control. MFC is the lowest concentration of essential oil, which causes $100 \%$ death of fungal cells. MCF was evaluated after transferring the fungal disc containing from the oil modified medium to a clean CYA medium without essential oil. Plates with a transferred disk were incubated at $25^{\circ} \mathrm{C}$ for 10 days. The growth of mycelium was considered as a result of the fungistatic activity of the oil, meanwhile the lack of mycelial growth was recorded as fungicidal activity of essential oil (Kumar et al., 2007).

\section{Results}

The effect of the tested essential oils on the growth of selected fungi was varied and depended on susceptibility of fungal strain and/or the concentration and type of essential oil. The qualitative and quantitative composition of essential oils determined their disinfecting effect. Results of GC-MS analysis showed significant differences in composition of individual oils. All tested oils contained 
compounds belonging to the terpene group. The compounds were divided into groups based on their chemical structure. The content of aliphatic, mono-, bi-, tricyclic monoterpenes and sesquiterpenes in the essential oils is presented in Table 1. The content of oxygenated derivatives of monoterpenes was shown in Table 2.
Rosewood oil had only oxygenated terpenes, and the main ingredient was linalool (80\%). Thyme oil was characterized by a high content of phenols belonging to monoterpenes with thymol as the dominant substance $(46 \%$ of the essential oil). Rosemary oil, unlike the rosemary and thyme oils, had high level of bi- and tri-cyclic monoterpenes (about 33\%). The main ingredients were camphor (16\%),

Table 1. Content of mono- and sesquiterpens in the essential oils from rosewood, thyme and rosemary

\begin{tabular}{|c|c|c|c|}
\hline & $\begin{array}{c}\text { Rosewood } \\
\text { essential oil }[\%]\end{array}$ & $\begin{array}{c}\text { Thyme } \\
\text { essential oil [\%] }\end{array}$ & $\begin{array}{c}\text { Rosemary } \\
\text { essential oil [\%] }\end{array}$ \\
\hline \multicolumn{4}{|c|}{ Aliphatic monoterpenes } \\
\hline$\beta$-mircen & 0.00 & 2.44 & 1.69 \\
\hline \multicolumn{4}{|c|}{ Monocyclic monoterpenes } \\
\hline Limonene & 0.00 & 15.15 & 0.00 \\
\hline$\alpha$ - Terpinene & 0.00 & 2.32 & 0.05 \\
\hline$\gamma$ - Terpinene & 0.00 & 8.10 & 2.18 \\
\hline Terpineol & 0.00 & 0.00 & 0.70 \\
\hline$\alpha$ - Phellandrene & 0.00 & 0.87 & 0.11 \\
\hline Total & 0.00 & 28.88 & 4.73 \\
\hline \multicolumn{4}{|c|}{$\mathrm{Bi}$ - and tricyclic monoterpenes } \\
\hline$\alpha$ - Pinene & 0.00 & 2.75 & 10.31 \\
\hline$\beta$ - Pinene & 0.00 & 0.65 & 7.72 \\
\hline Camphene & 0.00 & 1.93 & 8.22 \\
\hline$\alpha$-Thujene & 0.00 & 0.00 & 3.71 \\
\hline$\alpha$ - Cubenen & 0.00 & 0.00 & 0.15 \\
\hline$\beta$ - Cubenen & 0.00 & 0.00 & 0.14 \\
\hline$\alpha$-longipinen & 0.00 & 0.00 & 0.07 \\
\hline ylangen & 0.00 & 0.00 & 0.13 \\
\hline Copaen & 0.00 & 0.00 & 0.58 \\
\hline Longifolen & 0.00 & 0.00 & 0.56 \\
\hline$(+)$-aromadendrene & 0.00 & 0.00 & 0.09 \\
\hline$\gamma$-Cadinene & 0.00 & 0.00 & 0.31 \\
\hline$\delta$ - Cadinene & 0.00 & 0.00 & 0.38 \\
\hline$\gamma$-Murolene & 0.00 & 0.00 & 0.11 \\
\hline Tricyclene & 0.00 & 0.17 & 0.47 \\
\hline \multicolumn{4}{|c|}{ Sesquiterpenes } \\
\hline$\alpha$-Caryophyllene & 0.00 & 4.71 & 9.01 \\
\hline Izocaryophyllene & 0.00 & 0.00 & 0.04 \\
\hline Total & 0.00 & 4.71 & 9.05 \\
\hline
\end{tabular}


eucalyptol (16\%), $\alpha$-pinene (10\%), camphene $(8 \%)$ and $\beta$-pinene (about 8\%).

As mentioned previously, the fungistatic activity of the tested oils depended on nature ans concentration of the oil, and on the susceptibility of the tested moulds (Table 3). Thyme essential oil showed the highest effective inhibition of mycelial growth, and at concentration of $1 \mu \mathrm{L} \mathrm{mL}^{-1}$ showed a fungistatic effect on all tested isolates. Rosewood essential oil caused complete inhibition of Penicillium citrinum growth at concentration of $1 \mu \mathrm{L} \mathrm{mL}^{-1}$, and isolates of Acremonium strictum and Purpureocillium lilacinum at concentration of $5 \mu \mathrm{L} \mathrm{mL}^{-1}$. Penicillium expansum was less susceptible to rosewood essential oil which inhibited its growth at concentration of $10 \mu \mathrm{L} \mathrm{mL} \mathrm{m}^{-1}$. The most varied fungistic activity was shown by rosemary essential oil. This oil showed biocidal activity against Penicillium expansum in the highest tested concentration of $20 \mu \mathrm{L} \mathrm{mL}^{-1}$. In contrast, the development of the mycelium of Purpureo- cillium lilacinum was inhibited at a concentration of $15 \mu \mathrm{L}$ $\mathrm{mL}^{-1}$, while Acremonium strictum at a concentration of $10 \mu \mathrm{L} \mathrm{mL}^{-1}$. Disinfectant containing $3 \mu \mathrm{L} \mathrm{mL}^{-1}$ of peracetic acid inhibited growth of Acremonium strictum and Penicillium citrinum (Table 3 ).

Compared to the negative control, all tested oils reduced the rate of mycelial growth. The thyme oil showed the most effective antifungal activity, regardless of the applied concentration of oil. Growth of all tested fungal strains was completely inhibited after treatment with that oil. The presence of rosewood oil at concentration of $1 \mu \mathrm{L}$ $\mathrm{mL}^{-1}$ affect the decrease of mycelial growth of $P$. expansum and $P$. lilacinum by about $60 \%$. Rosemary essential oil in concentrations above $1 \mu \mathrm{L} \mathrm{mL}^{-1}$, had only decrease the growth of fungal mycelium for all tested strains. Disinfectant containing peracetic acid did not change the growth rate of fungal mycelium of following strains: $P$. expansum and P. lilacinum (Table 4).

Table 2. Content of oxygenated derivatives of mono- and sesquiterpens in the essential oils from rosewood, thyme and rosemary

\begin{tabular}{|c|c|c|c|}
\hline & $\begin{array}{c}\text { Rosewood } \\
\text { essential oil [\%] }\end{array}$ & $\begin{array}{c}\text { Thyme } \\
\text { essential oil [\%] }\end{array}$ & $\begin{array}{c}\text { Rosemary } \\
\text { essential oil [\%] }\end{array}$ \\
\hline \multicolumn{4}{|c|}{ Oxygenated aliphatic monoterpenes } \\
\hline Linalool & 80.42 & 8.90 & 1.83 \\
\hline cis-Linalool oxide & 4.51 & 0.00 & 0.00 \\
\hline trans-Linalool oxide & 1.15 & 0.00 & 0.00 \\
\hline Dihydrolinalool & 1.20 & 0.00 & 0.00 \\
\hline Linalyl acetate & 4.07 & 0.00 & 0.00 \\
\hline Eucalyptol & 7.42 & 15.15 & 15.75 \\
\hline Thymol & 0.00 & 45.75 & 0.00 \\
\hline Camphor & 0.00 & 0.00 & 16.13 \\
\hline Bergamol & 0.00 & 0.93 & 0.00 \\
\hline Borneol & 0.00 & 3.00 & 7.99 \\
\hline Bornyl acetate & 0.00 & 0.00 & 3.46 \\
\hline Fenchol & 0.00 & 0.00 & 0.08 \\
\hline Fenchyl acetate & 0.00 & 0.00 & 0.54 \\
\hline$\alpha$-Terpineol & 1.23 & 2.33 & 5.64 \\
\hline 1-Terpinen-4-ol & 0.00 & 0.00 & 1.40 \\
\hline Total & 100.00 & 76.06 & 51 \\
\hline \multicolumn{4}{|c|}{ Oxygenated sesquiterpenes } \\
\hline Caryophyllene oxide & 0.00 & 0.00 & 0.28 \\
\hline Total & 0.00 & 0.00 & 0.28 \\
\hline
\end{tabular}


Table 3. Antifungal activity of tested essential oils expressed as a rate of growth inhibition [\%]

\begin{tabular}{|c|c|c|c|c|}
\hline \multirow{3}{*}{$\begin{array}{c}\text { Concentration } \\
\text { formulation } \\
{\left[\mu \mathrm{L} \cdot \mathrm{mL}^{-1}\right]}\end{array}$} & \multicolumn{4}{|c|}{ Rate of growth inhibition (I) $[\% \pm \mathrm{SD}]$} \\
\hline & \multicolumn{4}{|c|}{ Used formulation } \\
\hline & Disinfectant & $\begin{array}{c}\text { Thyme } \\
\text { essential oil }\end{array}$ & $\begin{array}{l}\text { Rosewood } \\
\text { essential oil }\end{array}$ & $\begin{array}{c}\text { Rosemary } \\
\text { essential oil }\end{array}$ \\
\hline \multicolumn{5}{|c|}{ Acremonium strictum } \\
\hline 1 & - & $100.00 \pm 0.00$ & $83.59 \pm 0.90$ & $45.94 \pm 4.72$ \\
\hline 3 & $58.13 \pm 4.12$ & - & - & - \\
\hline 5 & - & $100.00 \pm 0.00$ & $100.00 \pm 0.00$ & $51.88 \pm 13.50$ \\
\hline 10 & - & $100.00 \pm 0.00$ & $100.00 \pm 0.00$ & $100.00 \pm 0.00$ \\
\hline 15 & - & $100.00 \pm 0.00$ & $100.00 \pm 0.00$ & $100.00 \pm 0.00$ \\
\hline 20 & - & $100.00 \pm 0.00$ & $100.00 \pm 0.00$ & $100.00 \pm 0.00$ \\
\hline \multicolumn{5}{|c|}{ Penicillium citrinum } \\
\hline 1 & - & $100.00 \pm 0.00$ & $100 \pm 0.00$ & $63.86 \pm 9.02$ \\
\hline 3 & $25.60 \pm 3.32$ & - & - & - \\
\hline 5 & - & $100.00 \pm 0.00$ & $100.00 \pm 0.00$ & $100 \pm 0.00$ \\
\hline 10 & - & $100.00 \pm 0.00$ & $100.00 \pm 0.00$ & $100 \pm 0.00$ \\
\hline 15 & - & $100.00 \pm 0.00$ & $100.00 \pm 0.00$ & $100 \pm 0.00$ \\
\hline 20 & - & $100.00 \pm 0.00$ & $100.00 \pm 0.00$ & $100 \pm 0.00$ \\
\hline \multicolumn{5}{|c|}{ Penicillium expansum } \\
\hline 1 & - & $100.00 \pm 0.00$ & $61.66 \pm 3.85$ & $37.91 \pm 4.24$ \\
\hline 3 & $0.00 \pm 0.00$ & - & - & - \\
\hline 5 & - & $100.00 \pm 0.00$ & $92.73 \pm 8.91$ & $46.41 \pm 1.07$ \\
\hline 10 & - & $100.00 \pm 0.00$ & $100.00 \pm 0.00$ & $65.34 \pm 2.17$ \\
\hline 15 & - & $100.00 \pm 0.00$ & $100.00 \pm 0.00$ & $94.12 \pm 2.63$ \\
\hline 20 & - & $100.00 \pm 0.00$ & $100.00 \pm 0.00$ & $100.00 \pm 0.00$ \\
\hline \multicolumn{5}{|c|}{ Purpureocillium lilacinum } \\
\hline 1 & - & $100.00 \pm 0.00$ & $59.38 \pm 0.72$ & $8.05 \pm 0.00$ \\
\hline 3 & $0.00 \pm 0.00$ & - & - & - \\
\hline 5 & - & $100.00 \pm 0.00$ & $100.00 \pm 0.00$ & $60.53 \pm 1.74$ \\
\hline 10 & - & $100.00 \pm 0.00$ & $100.00 \pm 0.00$ & $84.67 \pm 1.44$ \\
\hline 15 & - & $100.00 \pm 0.00$ & $100.00 \pm 0.00$ & $100.00 \pm 0.00$ \\
\hline 20 & - & $100.00 \pm 0.00$ & $100.00 \pm 0.00$ & $100.00 \pm 0.00$ \\
\hline
\end{tabular}


Table 4. Index of growth rate for tested molds. Values were estimated only for these concentration of essential oils which did not inhibit growth of mycelium $\left[\mathrm{mm} \cdot \mathrm{day}^{-1}\right]$

\begin{tabular}{|c|c|c|c|c|c|}
\hline \multirow{3}{*}{$\begin{array}{c}\text { Concentration } \\
\text { formulation } \\
{\left[\boldsymbol{\mu} \mathrm{L} \cdot \mathrm{mL}^{-1}\right]}\end{array}$} & \multicolumn{5}{|c|}{ Index of growth rate $(\mathrm{T})\left[\mathrm{mm} \cdot \mathrm{day}^{-1}\right]$} \\
\hline & \multicolumn{5}{|c|}{ Used formulation } \\
\hline & Control & Disinfectant & $\begin{array}{c}\text { Thyme } \\
\text { essential oil }\end{array}$ & $\begin{array}{l}\text { Rosewood } \\
\text { essential oil }\end{array}$ & $\begin{array}{c}\text { Rosemary } \\
\text { essential oil }\end{array}$ \\
\hline \multicolumn{6}{|c|}{ Acremonium strictum } \\
\hline & $88.00 \pm 0.00$ & - & - & - & - \\
\hline 1 & - & - & $0.00 \pm 0.00$ & $14.43 \pm 0.81$ & $47.58 \pm 4.15$ \\
\hline 3 & - & $36.85 \pm 3.62$ & - & - & - \\
\hline 5 & - & - & - & - & $42.35 \pm 6.06$ \\
\hline \multicolumn{6}{|c|}{ Penicillium citrinum } \\
\hline & $45.65 \pm 0.78$ & - & - & - & - \\
\hline 1 & - & - & $0.00 \pm 0.00$ & - & $26.13 \pm 2.98$ \\
\hline 3 & - & $33.96 \pm 3.80$ & - & - & - \\
\hline \multicolumn{6}{|c|}{ Penicillium expansum } \\
\hline & $21.04 \pm 1.15$ & - & - & - & - \\
\hline 1 & - & - & $0.00 \pm 0.00$ & $8.07 \pm 1.90$ & $22.28 \pm 0.89$ \\
\hline 3 & - & $21.04 \pm 1.30$ & - & - & - \\
\hline 5 & - & - & - & - & $11.28 \pm 0.22$ \\
\hline 10 & - & - & - & - & $7.29 \pm 0.45$ \\
\hline 15 & - & - & - & - & $1.24 \pm 0.06$ \\
\hline \multicolumn{6}{|c|}{ Purpureocillium lilacinum } \\
\hline & $35.89 \pm 0.32$ & - & - & - & - \\
\hline 1 & - & - & $0.00 \pm 0.00$ & $14.58 \pm 1.91$ & $33.00 \pm 0.00$ \\
\hline 3 & - & $35.89 \pm 0.26$ & - & - & - \\
\hline 5 & - & - & - & - & $14.16 \pm 0.63$ \\
\hline 10 & - & - & - & - & $5.50 \pm 0.52$ \\
\hline
\end{tabular}



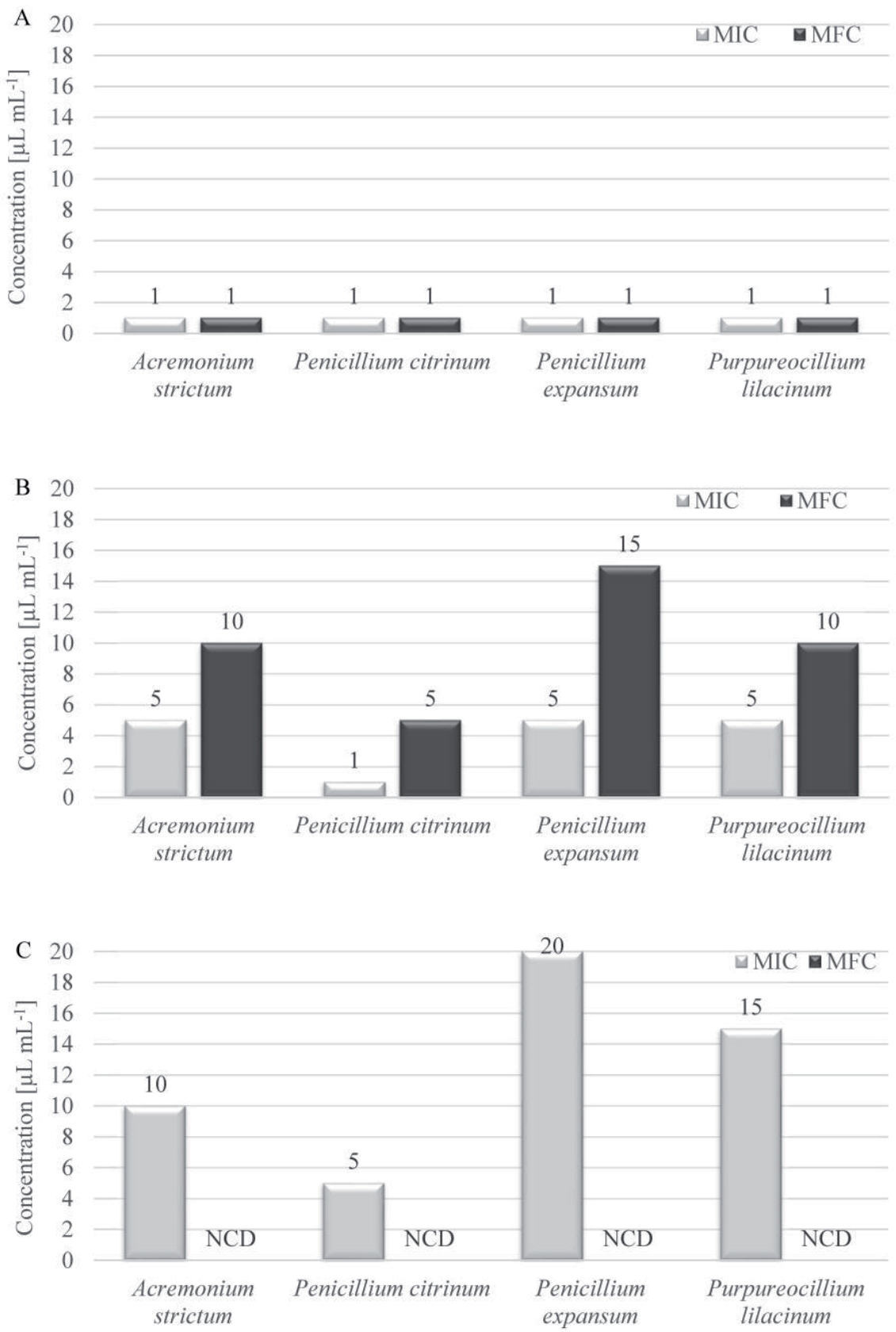

Figure 1. Minimum inhibitory concentration (MIC) and Minimum fungicidal concentration (MFC) for thyme essential oil (A), rosewood essential oil (B) and rosemary essential oil (C). *NCD-concentration was not estimated

The lowest MIC and MFC values of essential oils were found for thyme oil and were equal to $1 \mu \mathrm{L} \mathrm{mL}^{-1}$ (Fig. 1a). For rosewood and rosemary oil, the MIC and MFC values were varied for all strains. The most sensitive to rosewood essential oil was $P$. citrinum strain (MIC $=1 \mu \mathrm{L} \mathrm{mL}^{-1}$, MFC $\left.=5 \mu \mathrm{L} \mathrm{mL} \mathrm{m}^{-1}\right)$. In contrast, the highest resistance to rosewood oil was exhibited by $P$. expansum $\left(\mathrm{MIC}=5 \mu \mathrm{L} \mathrm{mL}^{-1}\right.$, $\mathrm{MFC}=15 \mu \mathrm{L} \mathrm{mL}^{-1}$ ) (Fig. 1b). Similarly, the most sensitive to rosemary oil was $P$. citrinum $\left(\mathrm{MIC}=5 \mu \mathrm{L} \mathrm{mL} \mathrm{L}^{-1}\right)$, while the most resistant $P$. expansum $\left(\mathrm{MIC}=20 \mu \mathrm{L} \mathrm{mL}^{-1}\right.$ ). Rosemary oil in the tested concentrations did not show fungicidal properties and MFC was not found (Fig. 1c).

\section{Discussion}

A growth of microbial resistance to the disinfection chemicals is the main reason for searching for alternative solu- 
tions ensuring the sterility of the production environment. Fungicidal activity of essential oils lead to increase of use this natural substances as disinfectants. The essential oils were used during storage process to eliminate fungi of $\mathrm{As}$ pergillus and Penicillium species from raw fruits and vegetables (Passone et al., 2013), and during food production proccess to eliminate the moulds such as Alternaria, Acremonium, Fusarium and Trichoderma which were present in the production environment. Moulds through the mycotoxins product may also adversely affect the quality of the stored raw materials and products and pose a health risk to workers (Gemeda et al., 2014b).

Biocidal activity of essential oils depends on their chemical composition, terpenes concentration and on the susceptibility of fungal strains (Krzyśko-Łupicka \& Walkowiak, 2014). Thyme and rosewood essential oils more effectively inhibited the mycelium growth of tested strains than rosemary essential oil. High activity of thyme oil may be associated with a high content of phenolic compounds as thymol (Abbaszadeh et al., 2014; Campos-Requena et al., 2015). Thymol is the main ingredient in thyme oil, and its content in essential oils depends on the quality of the raw material and growth conditions of thyme as well as from storage period (Jiang et al., 2011; Lemos et al., 2017). Some authors suggested that aromatic compounds containing polar functional groups exhibit antimicrobial activity (Lemos et al., 2017). Thymol has the phenolic hydroxyl groups which are highly reactive and form hydrogen bonds with active target enzymes leading to their inactivation (Ouattara et al., 1997).

The composition of thyme oil and rosemary oil was characterized by a high content of oxygeneganted monoterpenes. These substances have high antimicrobial activity (Białoń et al., 2014). Rosemary oil was predominantly comprised of bi- and tricyclic monoterpenes (32.98\%) when compared to rosewood $(0.00 \%)$ and thyme $(5.50 \%)$ essential oils, respectively. Hyldgaard et al. (2012) showed that such substances (monoterpenes) exhibited lower antimicrobial activity than their oxidized derivatives. The main ingredient of rosemary oil was linalool, which comprised of $80.42 \%$ of the essential oil content. Linalool as thymol is a substance belonging to monoterpenes. However, linalool was applied at higher concentrations than thymol for complete inhibition of fungal growth (Shin et al., 2014). There are reports of high fungicidal properties of linalool against Penicillium italicum (Shimada et al., 2014), as well as fungistatic activity of Penicillium ssp., Aspergillus ssp., and Fusarium ssp. (Marei et al., 2012). The various susceptibility of fungi to linalool can be resulted from their ability to biotransformation of this substance into other aromatic compounds (Molina et al., 2013).

There are some problems associated with the use of essential oils in practice, namely lack of data on the toxicity of essential oils from individual plants (due to the fact that essential oils are a mixture of many biologically active substances), changes in the composition of the oil depending on maturity, growth conditions or quality of the raw material from which the essential oil was extracted, short duration of active substances in the oil due to their volatile nature, and limited water solubility of terpenes and their derivatives (Wattanasatcha et al., 2012; Białoń et al., 2014).

\section{Conclusion}

The fungicidal and antifungal activity of the essential oils was dependent on the content of the active substances and the sensitivity of the fungal strains. The most effective inhibitor of fungal growth was the thyme essential oil and therefore it can be used as an active agent in a new generation of disinfectants. The most resistant to the tested essential oils was the Penicillium expansum strain, which suggest that it could be used as an indicator of the effectiveness of the disinfection process.

\section{Reference}

Abbaszadeh S., Sharifzadeh A., Shokri H., Khosravi A. R. \& Abbaszadeh A., 2014, Antifungal efficacy of thymol, carvacrol, eugenol and menthol as alternative agents to control the growth of food-relevant fungi. Journal of Medical Mycology 24(2): 51- 56.

Ajayi A. \& Fuchs R., 2015, Application of phytochemical extracts and essential oils in food products: A review. International Journal of Biotechnology and Food Science 3(3): 31-35.

Białoń M., Krzyśko-Łupicka T., Koszałkowska M. \& Wieczorek P.P., 2014, The influence of chemical composition of commercial lemon essential oils on the growth of Candida strains. Mycopathologia 177(1-2): 29-39.

Borecki Z., 1984, Fungicydy stosowane w ochronie roślin [Fungicides used in plant protection]. PWN, Warszawa.

Burt S., 2004, Essential oils: their antibacterial properties and potential applications in foods - a review. International Journal of Food Microbiology 94(3): 223-253.

Campos-Requena V.H., Rivas B.L., Pérez M.A., Figueroa C.R. \& Sanfuentes E.A., 2015, The synergistic antimicrobial effect of carvacrol and thymol in clay/polymer nanocomposite films over strawberry gray mold. LWT - Food Science and Technology 64(1): 390-396.

Feng W., Chen J., Zheng X. \& Liu Q., 2011, Thyme oil to control Alternaria alternata in vitro and in vivo as fumigant and contact treatments. Food Control 22(1): $78-81$. 
Gemeda N., Woldeamanuel Y., Asrat D. \& Debella A., 2014a, Effect of Cymbopogon martinii, Foeniculum vulgare, and Trachyspermum ammi essential oils on the growth and mycotoxins production by Aspergillus species. International Journal of Food Science 2014 (6): $1-9$.

Gemeda N., Woldeamanuel Y., Asrat D. \& Debella A., 2014b. Effect of essential oils on Aspergillus spore germination, growth and mycotoxin production: a potential source of botanical food preservative. Asian Pacific Journal of Tropical Biomedicine 4(1): 373-381.

Gleń K. \& Boligłowa E., 2012, The effect of extracts from herbal plants on dominating species of fungi colonizing broad bean seeds. Journal of Research and Applications in Agricultural Engineering 57(3): 98-103.

Hyldgaard M., Mygind T. \& Meyer R.L., 2012. Essential oils in food preservation: mode of action, synergies, and interactions with food matrix components. Frontiers in Microbiology 3(12): 1-24.

Jiang Y., Wu N., Fu Y., Wang W., Luo M., Zhao C., Zu Y. \& Liu X., 2011, Chemical composition and antimicrobial activity of the essential oil of rosemary. Environmental Toxicology and Pharmacology 32(1): 63-68.

Kedia A., Prakash B., Mishra P.K., Dwivedy A.K. \& Dubey N.K., 2015, Trachyspermum ammi L. essential oil as plant based preservative in food system. Industrial Crops and Products 69: 104-109.

Kohiyama C.Y., Yamamoto Ribeiro M.M., Mossini S.A.G., Bando E., Bomfim N.S., Nerilo S.B., Rocha G.H.O., Grespan R., Mikcha J.M.G. \& Machinski M., Jr., 2015, Antifungal properties and inhibitory effects upon aflatoxin production of Thymus vulgaris L. by Aspergillus flavus Link. Food Chemistry 173: 1006-1010.

Krzyśko-Łupicka T. \& Walkowiak W., 2014, Evaluation of susceptibility of phytopathogenic Fusarium culmorum strain on selected essential oils. Ecological Chemistry and Engineering A 21(3): 355-366

Kumar R., Dubey N.K., Tiwari O.P., Tripathi Y.B. \& Sinha K.K., 2007, Evaluation of some essential oils as botanical fungitoxicants for the protection of stored food commodities from fungal infestation. Journal of the Science of Food and Agriculture 87(9): 1737-1742.

Lemos M.F., Lemos M.F., Pacheco H.P., Guimarães A.C., Fronza M., Endringer D.C. \& Scherer R., 2017, Seasonal variation affects the composition and antibacterial and antioxidant activities of Thymus vulgaris. Industrial Crops and Products 95: 543-548.

Lima G., Sanzani S., Curtis F. \& Ippolito A., 2015, Biological control of postharvest diseases, [in:] R. Wills, J. Golding (eds), Advances in postharvest fruit and vegetable technology. Contemporary Food Engineering, London: 65-88.

Marei G.I.Kh., Abdel Rasoul M.A. \& Abdelgaleil S.A.M., 2012, Comparative antifungal activities and biochemical effects of monoterpenes on plant pathogenic fungi. Pesticide Biochemistry and Physiology 103: 56-61

Molina G., Pinheiro D.M., Pimentel M.R., dos Ssanros R. \& Pastore G.M., 2013, Monoterpene bioconversion for the production of aroma compounds by fungi isolated from Brazilian fruits. Food Science and Biotechnology 22(4): 999-1006.

Ouattara B., Simard R.E., Holley R.A., Piette G.J.P. \& Bégin A., 1997, Antibacterial activity of selected fatty acids and essential oils against six meat spoilage organisms. International Journal of Food Microbiology 37(2-3): 155-162.

Passone M.A., Girardi N.S. \& Etcheverry M., 2013, Antifungal and antiaflatoxigenic activity by vapor contact of three essential oils, and effects of environmental factors on their efficacy. LWT - Food Science and Technology 53(2): 434-444.

Pereira V.L., Fernandes J.O. \& Cunha S.C., 2014, Mycotoxins in cereals and related foodstuffs: A review on occurrence and recent methods of analysis. Trends in Food Science \& Technology 36(2): 96-136.

Raut J.S. \& Karuppayil S.M., 2014, A status review on the medicinal properties of essential oils. Industrial Crops and Products 62: 250-264.

Shimada T., Endo T., Fujii H., Rodríguez A., Peña L. \& Omura M., 2014, Characterization of three linalool synthase genes from Citrus unshiu Marc. and analysis of linalool-mediated resistance against Xanthomonas citri subsp. citri and Penicilium italicum in citrus leaves and fruits. Plant Science 229: 154-166.

Shin M.H., Kim J.H., Choi H.W., Keum Y.S. \& Chun S.C., 2014, Effect of thymol and linalool fumigation on postharvest diseases of table grapes. Mycobiology 42(3): 262-268.

Soliman K.M. \& Badeaa R.I., 2002, Effect of oil extracted from some medicinal plants on different mycotoxigenic fungi. Food and Chemical Toxicology 40(11): 16691675.

U.S. Code of Federal Regulations (CFR), 2015, Title 21, Part 182, Section. 182, 20. (https:/www.accessdata.fda.gov/scripts/cdrh/cfdocs/cfcfr/CFRSearch. cfm?fr=182.20), [Assessed on 15/09/2017].

Wattanasatcha A., Rengpipat S. \& Wanichwecharungruang S., 2012, Thymol nanospheres as an effective antibacterial agent. International Journal of Pharmaceutics 434(1-2): 360-365. 